\title{
Effect of psychoneural factors on intestinal epithelial function
}

\author{
M Cecilia Berin MSc, Mary H Perdue PhD
}

\begin{abstract}
MC Berin, MH Perdue. Effect of psychoneural factors on intestinal epithelial function. Can J Gastroenterol 1997;11(4):353-357. Stress has been associated with abnormal gastrointestinal function, including diarrhea and abdominal pain, and stress-associated gastric ulceration has frequently been documented. Stress can also exacerbate ongoing pathophysiology and often precedes relapses in patients with inflammatory bowel disease or irritable bowel syndrome. The relatively new field of psychoneuroimmunology is involved with the elucidation of mechanisms that explain the link between the central nervous system and immune-mediated pathophysiology. Recent progress examining the interaction among the nervous system, the immune system and the epithelium of the intestine is discussed, and the evidence for central nervous sysytem control of this interaction is examined.
\end{abstract}

Key Words: Abnormal gastrointestinal function, Intestinal epithelium, Psychoneuroimmunology, Stress

\section{Effet des facteurs psychoneuraux sur la fonction épithéliale intestinale}

RÉSUMÉ : Le stress a été associé à la dysfonction gastrointestinale, y compris à la diarrhée et à la douleur abdominale et des ulcères gastriques associés au stress ont souvent été documentés. Le stress peut également exacerber la physiopathologie existante et précède souvent la rechute chez des patients atteints de maladie inflammatoire de l'intestin ou du syndrome du côlon irritable. Nouveau domaine de recherche, la psychoneuro-immunologie se penche sur l'élucidation des mécanismes pouvant expliquer le lien entre le système nerveux central et la physiopathologie à médiation immunitaire. De récents progrès réalisés grâce à l'examen d'une interaction entre le système nerveux, le système immunitaire et l'épithélium intestinal sont abordés ici, de même que certaines preuves du contrôle de cette interaction par le système nerveux central.

(CNS) and immune-mediated pathophysiology. This review discusses recent progress examining the interaction among the nervous system, the immune system and the epithelium of the intestine, and examines the evidence for CNS control of this interaction.

\section{INTESTINAL EPITHELIUM}

The intestine is lined with a single layer of epithelial cells that form a barrier between the lumen contents and the interstitium. The epithelial layer has two main roles: transport and barrier functions. Tight junctions between enterocytes

This paper was part of a symposium entitled "Selected topics in pediatric gastroenterology and nutrition" held in October 1995 to honour the academic career of Dr Gordon G Forstner

Intestinal Disease Research Program, Department of Pathology, McMaster University, Hamilton, Ontario

Correspondence and reprints: Dr MH Perdue, Intestinal Disease Research Program, McMaster University, HSC-3N5C, 1200 Main Street West, Hamilton, Ontario L8N 325. Telephone 905-525-9140 ext 22585, fax 905-522-3454, e-mail perdue@fhs.mcmaster.ca 
form a selective high resistance barrier that restricts passive permeation of molecules. Small ions and water can penetrate through the tight junctions, but uptake of macromolecules and bacteria or bacterial products is kept to a minimum. In pathophysiological situations, the permeability of the epithelial layer has been observed to increase, allowing a greater amount of antigen to cross into the lamina propria which may allow chronic immunological activation.

Epithelial cells also are responsible for absorption and secretion of water and ions. Enterocytes are derived from stem cells in the crypt region, and over several days they migrate from the crypt to the villus. As they migrate, their phenotype changes from a predominantly secretory cell in the crypt to an absorptive phenotype on the villus. Absorption of ions, water and nutrients is linked to the $\mathrm{Na} / \mathrm{K}$-ATPase enzyme (sodium ion pump) found in the basolateral membrane of enterocytes. The pump maintains a low concentration of sodium ions inside the cell, which links absorption of nutrients to the flow of sodium ions down their concentration gradient into the cell. Secretory processes consist mainly of chloride ion secretion via chloride channels, such as the cystic fibrosis transmembrane conductance regulator channel in the apical membrane, and water follows the flow of chloride ions into the gut lumen. Excess secretion and reduced absorption in the intestine lead to diarrhea, a common symptom of a number of inflammatory gastrointestinal diseases.

\section{ENTERIC NERVOUS SYSTEM}

The autonomic nervous system is important in regulating gastrointestinal function. It consists of three main divisions: the sympathetic, parasympathetic and enteric nervous systems. The enteric nervous system, termed the 'little brain', processes sensory information from the gastrointestinal tract and controls motor and secretory responses to maintain homeostasis. The sympathetic and parasympathetic nervous system provide an 'override' system in order to maintain homeostasis between the different organ systems.

The enteric nervous system consists of neurons within the myenteric and submucosal plexuses. The myenteric plexus has classically been defined as the controller of motor response, while the submucous plexus is involved with control of secretory tone. For appropriate regulation of intestinal physiology, secretion and motor activity need to be synchronized, indicating the requirement for communication between the plexuses. Receptors in the intestinal wall transduce chemical or mechanical stresses, and initiate reflexes that alter the motor and secretory activity of the intestine.

Enteric neurons can be classified by the type of neurotransmitter(s) they contain. There are a vast number of different neurotransmitters in the gut, but only a small number have been characterized by their function in the gut. Neurotransmitters that have a direct action on the epithelial cells include acetylcholine, serotonin, noradrenaline, vasoactive intestinal polypeptide, neuropeptide $\mathrm{Y}$, somatostatin and substance P. These have been characterized as either prosecretory (acetylcholine, serotonin, vasoactive intestinal polypeptide, substance $\mathrm{P}$ ) or pro-absorptive (neuropeptide Y, somatostatin, noradrenaline) (4). Obviously the potential exists for neuronal control of epithelial function. This has been clearly demonstrated for the regulation of ion transport, but there is a lack of information regarding the effect of nerves and individual neurotransmitters on the barrier function of the epithelium.

\section{IMMUNE CELLS OF THE MUCOSA}

Within the mucosa is found an abundance of immune cells. Immune cells are diffusely spread throughout the mucosa or are aggregated in follicles or within the epithelium. Mast cells are found throughout the intestinal wall, and their numbers increase significantly during nematode infection or following sensitization to food antigens (5). Mast cell granules contain several mediators that can alter intestinal physiology, including histamine, serotonin, proteases, tumour necrosis factor-alpha and prostaglandins. Mediators are released upon activation of the mast cell through crosslinking by antigen of immunoglobulin (Ig) E bound to the mast cell surface through high affinity receptors (FceRI). Phagocytes, including macrophages and neutrophils, are found throughout the intestinal mucosa. These cells are the first line of defence against bacterial infection and produce a wide array of inflammatory mediators including proteases, reactive oxygen metabolites, platelet activating factor and cytokines. Lymphocytes are also distributed throughout the mucosa and in organized follicles and Peyer's patches. B lymphocytes express antibody on their surface, and when stimulated by antigen and appropriate $\mathrm{T}$ lymphocyte cytokines, can differentiate into plasma cells and produce large quantities of antigen-specific antibodies. T lymphocytes of both the $\mathrm{CD}^{+}$(helper lymphocytes) and the $\mathrm{CD}^{+}$(cytotoxic/suppressor) subtypes are present in the intestinal mucosa, where they can produce a variety of cytokines that influence antibody production and immune cell proliferation. Lymphocytes are also found within the epithelium (intraepithelial leukocytes). These cells are in an ideal position for enterocyte regulation, but their role in immune-epithelial interaction has yet to be defined. However, many of the mediators and cytokines produced by these cells have been shown to alter epithelial physiology.

\section{NEURONAL INVOLVEMENT IN INTESTINAL PATHOPHYSIOLOGY}

Model systems: One means of studying the regulation of epithelial physiology is through a pathophysiological model. Perdue and Gall (6) used a model of intestinal anaphylaxis in the rat. Injection of egg albumin (EA) with co-administered adjuvants induced hypersensitivity to EA within approximately two weeks. EA challenge of the intestine cross-links IgE bound to mast cells and induces release of mediators that stimulate a secretory state via direct and indirect effects on the epithelium. Over the past 10 years experiments have revealed that nerves can amplify epithelial pathophysiology by interacting with immune cells in a bidirectional fashion. 


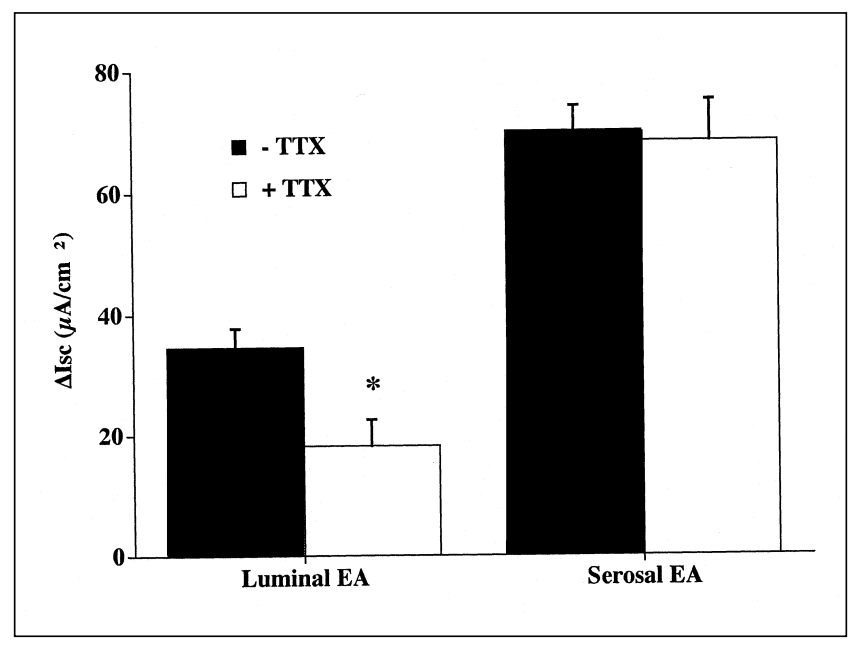

Figure 1) Effect of tetrodotoxin (TTX) on short-circuit current (Isc) responses to luminal or serosal antigen in jejunum from sensitized rats. Values represent maximum change in Isc expressed as means \pm SEM after egg albumin (EA) added to the luminal or serosal sides of jejunum from a total of 18 sensitized rats. Tissues were treated with $5 \times 10^{-6} \mathrm{M}$ TTX added to the serosal buffer 15 mins before antigen or left untreated. *P<0.05 compared with untreated

Nerves and immunophysiology: Nerve involvement in the hypersensitivity response has been demonstrated in several animal models of anaphylaxis. Castro et al (7) used the Trichinella spiralis parisitized rat model of hypersensitivity to show the involvement of nerves in the epithelial secretory response. Experiments were carried out in Ussing chambers, which measure changes in short-circuit current $(\Delta \mathrm{Isc})$ across voltage clamped tissues as a measure of net ion transport. The neurotoxin, tetrodotoxin (TTX), inhibited the $\Delta$ Isc induced by challenge with worm antigen. Atropine was similarly able to inhibit the response to antigen, indicating an important role for cholinergic neurons.

A second model of intestinal hypersensitivity, that induced by beta-lactoglobulin in milk-fed guinea pigs (8), provided results that confirmed those found in the $T$ spiralis model. From the above data, it can be postulated that nerves may amplify secretory responses initiated through IgEmediated mast cell degranulation.

The present authors provided evidence for the ability of nerves to regulate the barrier function of the epithelium. One of the advantages of the EA sensitized rat model is that isolated intestinal segments display consistent secretory responses to luminal antigen (9), which allows study of antigen uptake across the epithelium. In 1993 Crowe et al (10) used the EA model to establish the importance of nerves in the intestinal response to luminal antigen. TTX added to the serosal side of the tissue inhibited the response to luminal antigen, but not to serosal antigen (Figure 1). Epithelial permeability was also assessed in vivo by measurement of ${ }^{51} \mathrm{Cr}$ EDTA passage from gut lumen to blood and urine. Antigen uptake was determined by immunoassay of intact EA in serum. Challenge with EA produced a 15 -fold increase in probe uptake and a 14-fold increase in EA uptake in sensitized rats compared with controls. This was significantly in-

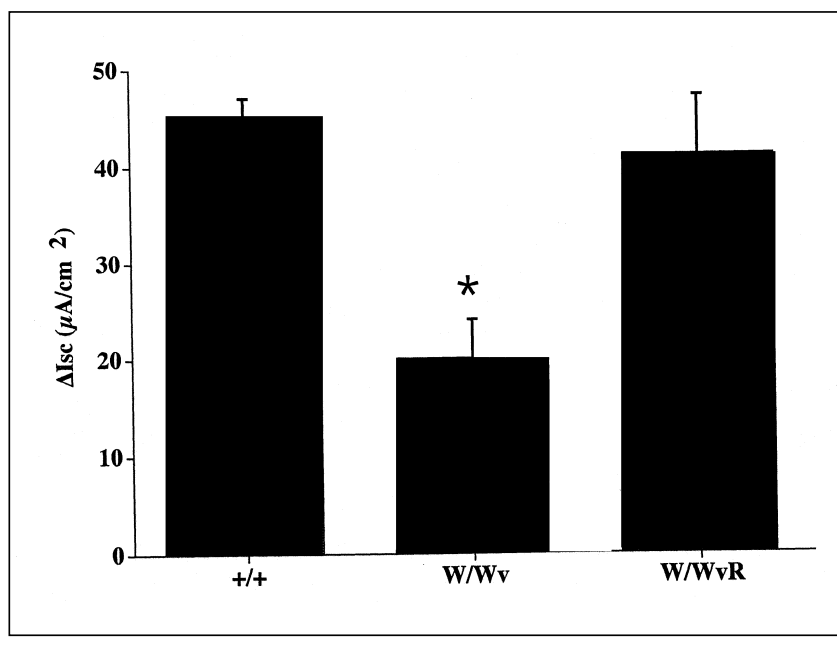

Figure 2) Effect of mast cells on short-circuit current (Isc) responses to transmural stimulation. Values represent means \pm SEM. $n=43$ for $+/+$, $n=26$ for $W / W^{v}$ and $n=14$ for bone marrow-reconstituted $W / W^{v}$ $(\mathrm{W} / \mathrm{W} v \mathrm{R})$ mice. The transmural stimulation response was the difference between the peak Isc after transmural stimulation and the baseline value. $* P<0.05$ compared with $+/+$ controls

hibited by TTX applied to the serosal surface of ligated segments of small intestine. The ability of TTX to inhibit responses to luminal, but not serosal, EA provides support for the hypothesis that nerves can regulate barrier function involving penetration of protein macromolecules. Further studies in the authors' laboratory used other neural inhibitors to characterize the types of nerves playing a role in the hypersensitivity response. Peptidergic nerves were implicated in the EA model because neonatal capsaicin treatment (which depletes substance $\mathrm{P}$ and calcitonin gene-related peptide containing nerves) was able to inhibit the secretory response to luminal antigen.

Examination of the role of nerves in epithelial barrier function has also been demonstrated in nonsensitized rodents. Phillips and colleagues (11) showed that cholinergic stimulation of rat intestine induced a large increase in movement of horseradish peroxidase through the tight junctions between enterocytes. Further evidence for neuronal control of macromolecular penetration through tight junctions comes from a study by Kimm et al (12) in which intact bovine serum albumin uptake across intestine was inhibited with TTX.

\section{NERVE-IMMUNE CELL INTERACTIONS}

A discussion of nerve regulation of epithelial function is not complete without consideration of the interplay between nerves and the immune compartment of the intestinal tract. It has been observed that nerves and mast cells are closely positioned within the intestinal mucosa (13). This close structural relationship suggests interplay between the two cell types, and functional studies have confirmed this hypothesis. The evidence for mast cell-nerve interaction comes from a number of different studies. Mast cells are responsive to substance $P$, found in enteric neurons (14). Janiszewski et 


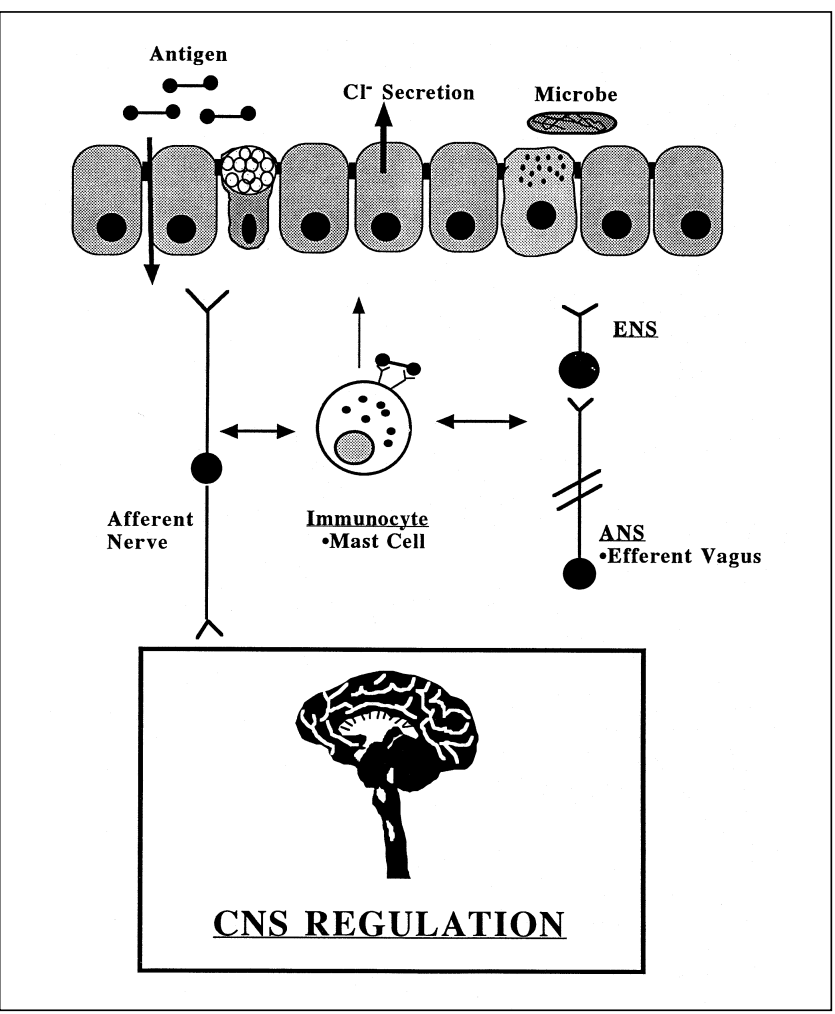

Figure 3) Diagrammatic schema illustrating neuroimmune interactions that regulate epithelial function, including regulation of both neuronal and immune compartments by the central nervous system (CNS). ANS Autonomic nervous system; ENS Enteric nervous system

al (15) co-cultured peritoneal mast cells with sympathetic neurons and found that mast cell activation resulted in neuronal excitation. Vagal stimulation has been shown to induce tracheal and bronchial mast cell degranulation (16). Communication from mast cell to nerve has also been demonstrated by Greene et al (17), who observed that IgEinduced mast cell degranulation causes vagal sensory neuron excitation. Histamine $\mathrm{H}_{3}$ receptors have been shown to be located on nerves in the colon (18).

Evidence for mast cell-nerve interaction occurring in the intestine was provided by Perdue and co-workers (19) in 1991 , in a study of mast cell deficient $\mathrm{W} / \mathrm{W}^{\mathrm{v}}$ mice and congenic controls. Intestine from these mice was removed and mounted in Ussing chambers for measurement of electrophysiological parameters. Transmural stimulation of intestinal nerves resulted in a $\Delta$ Isc that was significantly lower in $\mathrm{W} / \mathrm{W}^{\mathrm{v}}$ mice versus controls. The reintroduction of mast cells through bone marrow transplantation from control mice brought the transmural stimulation response back to normal values (data are presented in Figure 2). This result demonstrates that nerves are capable of degranulating mast cells, which can then contribute to the alteration of epithelial function.

Mast cells are not the only immune cells capable of interaction with the nervous system. Although mast cells have been shown to be central to intestinal disorders involving hypersensitivity reactions, other intestinal disorders appear to involve different immune cells. For example, elevated T lymphocyte cytokines and altered populations of lymphocytes and macrophages are associated with inflammatory bowel disease (20). Innervation of lymphoid follicles has been demonstrated (21), and lymphocyte sensitivity to neurotransmitters and nerve responsiveness to cytokines also supports the idea of immune-nerve cooperation beyond the hypersensitivity models.

\section{CNS REGULATION OF EPITHELIAL FUNCTION}

Pavlovian conditioning studies: It is clear that enteric nerves can modulate epithelial physiology. The present authors postulated that the CNS should be able to affect epithelial function by interacting with the enteric nervous system. One very important piece of evidence supporting the hypothesis that the CNS contributes to regulation of intestinal physiology comes from a study in which mast cells were conditioned to degranulate through Pavlovian conditioning (22). Rats sensitized to EA and repeatedly challenged in concert with an audiovisual cue, responded with mast cell degranulation to the audiovisual cue alone. The parameter measured was serum rat mast cell protease II, a protease specific to the mucosal mast cell, indicating that intestinal mast cells were degranulating in response to the prompt to the CNS.

Although this study provided strong evidence for the possibility of CNS control of intestinal physiology, further work was needed to show the connection between a conditioned stimulus and alteration of epithelial function. Subsequent studies with this model demonstrated that intestine from rats that had been exposed to the conditioning protocol and stimulated with the audiovisual cue $1 \mathrm{~h}$ before removal of the intestine, had a significantly increased baseline $\Delta \mathrm{Isc}$ (a measure of net ion transport), along with hyper-responsiveness to an EA challenge (23). This study provided definitive evidence for a pathway between the CNS and the intestinal epithelium. Pavlovian conditioning has also been shown to alter activation of other immune cells, including macrophages and lymphocytes (24), indicating that this effect is not limited to mast cell-enterocyte interaction.

Stress studies: Several studies have demonstrated that stress can induce gastric ulceration, but only recently has the effect of stress been examined in the small intestine. Psychological stress has been shown to alter fluid and electrolyte absorption in humans (25). A recent study indicated that stress can reactivate inflammation induced by trinitrobenzene sulphonic acid in the large intestine of rats (26), confirming observations in humans that stress can induce the relapse of inflammatory bowel disease. Another interesting piece of evidence indicating that stress contributes to intestinal pathophysiology comes from observations of the cottontop tamarin, a primate species that develops colitis in response to the stress of captivity (27). The present authors have been concerned with characterizing the effects of psychological stress on epithelial function in the rat and subsequently examining some of the pathways that may be responsible for this CNS-mucosal interaction.

Direct evidence for CNS regulation of epithelial function 
comes from studies in the authors' laboratory examining the effect of stress on intestinal function. The model of stress consists of restraining rats with or without a cold environment for $2 \mathrm{~h}$, followed by $2 \mathrm{~h}$ of rest in their home cage at room temperature. When intestine from these stressed rats was tested for electrophysiological changes in Ussing chambers, the baseline $\Delta \mathrm{Isc}$ was found to be significantly increased and the permeability of the epithelium to the probe ${ }^{51}$ Cr-EDTA was elevated (28). Mucosal nerve function was also altered, demonstrated by a decreased secretory response to transmural stimulation. This study provides clear support for the idea of CNS modulation of epithelial secretory and barrier function. Subsequent studies have shown that the increased permeability is not limited to small molecular weight probes because uptake of horseradish peroxidase $(44,000$ $\mathrm{kDa})$ was significantly increased in intestine from stressed rats compared with tissue from control rats (29).

The mechanism by which this decreased barrier function is induced by stress was subsequently examined. Because cholinergic stimulation was previously demonstrated to induce increased horseradish peroxidase movement across tight junctions in rats and parasympathetic 'overshoot'

\section{REFERENCES}

1. Wolf S, Wolff HG. Human Gastric Function. Oxford: Oxford Medical Publications, 1944.

2. Richter JE. Stress and psychological and environmental factors in functional dyspepsia. Scand J Gastroenterol Suppl 1991;182:40-6.

3. Duffy LC, Zielezny MA, Marshall JR, et al. Relevance of major stress events as an indicator of disease activity prevalence in inflammatory bowel disease. Behav Med 1991;17:101-10.

4. Cooke HJ. Neurobiology of the intestinal mucosa. Gastroenterology 1986;90:1057-81.

5. Perdue MH, Marshall J, Masson S. Ion transport abnormalities in inflamed rat jejunum. Involvement of mast cells and nerves. Gastroenterology 1990;98:561-7.

6. Perdue MH, Gall DG. Transport abnormalities during intestinal anaphylaxis in the rat: effect of anti-allergic agents. J Allergy Clin Immunol 1985:76:498-502.

7. Castro GA, Harari Y, Russell D. Mediators of anaphylaxis-induced ion transport changes in small intestine. Am J Physiol 1987;253:G540-8.

8. Javed NH, Want Y, Cooke HJ. Neuroimmune interactions: role for cholinergic neurons in intestinal anaphylaxis. Am J Physiol 1992;263:G847-52.

9. Crowe SE, Sestini P, Perdue MH. Allergic reactions of rat jejunal mucosa. Ion transport responses to luminal antigen and inflammatory mediators. Gastroenterology 1990;99:74-82.

10. Crowe SE, Soda K, Stanisz AM, Perdue MH. Intestinal permeability in allergic rats: nerve involvement in antigen-induced changes. Am J Physiol 1993;264:G617-23.

11. Phillips TE, Phillips TL, Neutra MR. Macromolecules can pass through occluding junctions of rat ileal epithelium during cholinergic stimulation. Cell Tissue Res 1987;247:547-54.

12. Kimm MH, Curtis GH, Hardin JA, Gall DG. Transport of bovine serum albumin across rat jejunum: The role of the enteric nervous system. Am J Physiol 1994;266:G186-93.

13. Stead RH, Dixon MF, Bramwell NH, Riddell RH, Bienenstock J. Mast cells are closely apposed to nerves in the human gastrointestinal mucosa. Gastroenterology 1989;97:575-85.

14. Shanahan F, Denburg JA, Fox J, Bienenstock J, Befus AD. Mast cell heterogeneity: effects of the neuroenteric peptides on histamine release. J Immunol 1985;135:1331-7.

15. Janiszewski J, Bienenstock J, Blennerhassett MG. Activation of rat peritoneal mast cells in coculture with sympathetic neurons alters neuronal physiology. Brain Behav Immun 1990;4:139-50.

16. Kiernan JA. Degranulation of mast cells in the trachea and bronchi mechanisms have been implicated in gastric ulcer disease, the role of cholinergic pathways was tested in this model. Injection of atropine before stress abolished the stress-induced changes to epithelial function, indicating that cholinergic neurons are involved in the pathway of CNS-induced epithelial alterations (29).

\section{CONCLUSIONS}

There is a mounting body of evidence for modulation of epithelial transport and barrier functions via bidirectional signalling between the CNS and mucosal nerves and immunocytes, as shown in Figure 3. The emergence of evidence for stress modulation of intestinal epithelial barrier function has very interesting implications, especially for gastrointestinal pathophysiology. It has been observed that stress can exacerbate or induce the flare-up of intestinal disease. We have demonstrated that stress increases epithelial permeability to macromolecules of antigenic size, which may promote or initiate pathogenic immune reactions in the mucosa. The interaction of nerves with the immune compartment may also amplify ongoing immune activation, leading to a cyclical aggravation of intestinal symptoms.

of the rat following stimulation of the vagus nerve. Int Arch Allergy Immunol 1990;91:398-402.

17. Greene R, Fowler J, MacGlashan DJ, Weinreich D. IgE-challenged human lung mast cells excite vagal sensory neurons in vitro. J Appl Physiol 1988;64:2249-53.

18. Frieling T, Cooke HJ, Wood JD. Histamine receptors on submucous neurons in guinea pig colon. Am J Physiol 1993;264:G74-80.

19. Perdue MH, Masson S, Wershil BK, Galli SJ. Role of mast cells in ion transport abnormalities associated with intestinal anaphylaxis. Correction of the diminished secretory response in genetically mast cell-deficient $\mathrm{W} / \mathrm{W}^{\mathrm{v}}$ mice by bone marrow transplantation. J Clin Invest 1991;87:687-93.

20. Podolsky DK. Inflammatory bowel disease. N Engl J Med 1991;325:928-37.

21. Felten SY, Felten DL. Innervation of lymphoid tissue. In: Ader R, Felten DL, Cohen N, eds. Psychoneuroimmunology. San Diego: Academic Press, 1991:27-69.

22. MacQueen G, Marshall J, Perdue MH, Siegel S, Bienenstock J. Pavlovian conditioning of rat mucosal mast cells to secrete rat mast cell protease II. Science 1989;243:83-5.

23. Djuric VJ, Bienenstock J, Perdue MH. Psychological and neural regulation of intestinal hypersensitivity. In: Berczi I, Szeleny J, eds. Advances in Psychoneuroimmunology. New York: Plenum Press, 1994:291-301.

24. Gorczynski RM. Conditioned immunosuppression: analysis of lymphocytes and host environment of young and aged mice. In: Ader R, Felten DL, Cohen N, eds. Psychoneuroimmunology. San Diego: Academic Press, 1991:647-62.

25. Barclay GR, Turnberg LA. Effect of psychological stress on salt and water transport in the human jejunum. Gastroenterology 1988;93:91-7.

26. Collins SM, McHugh K, Jacobson K, et al. Previous inflammation alters the response of the rat colon to stress. Gastroenterology 1996;111:1509-15.

27. Wood JD, Peck OC, Sharma HM, et al. Captivity promotes colitis in the cotton-top tamarin (Saguinus edipus). Gastroenterology 1990;98:A480.

28. Saunders PR, Kosecka U, McKay DM, Perdue MH. Acute stressors stimulate ion secretion and increase epithelial permeability in rat intestine. Am J Physiol 1994;267:G794-9.

29. Saunders PR, Kiliaan AJ, Groot JA, Bijlsma PB, Taminiau JA, Perdue $\mathrm{MH}$. Stress-enhanced epithelial permeability to antigenic proteins is mediated by cholinergic mechanisms and occurs via both transcellular and paracellular pathways. Gastroenterology 1995;108:A911. 


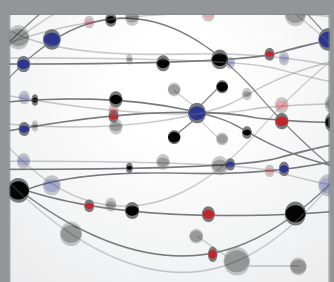

The Scientific World Journal
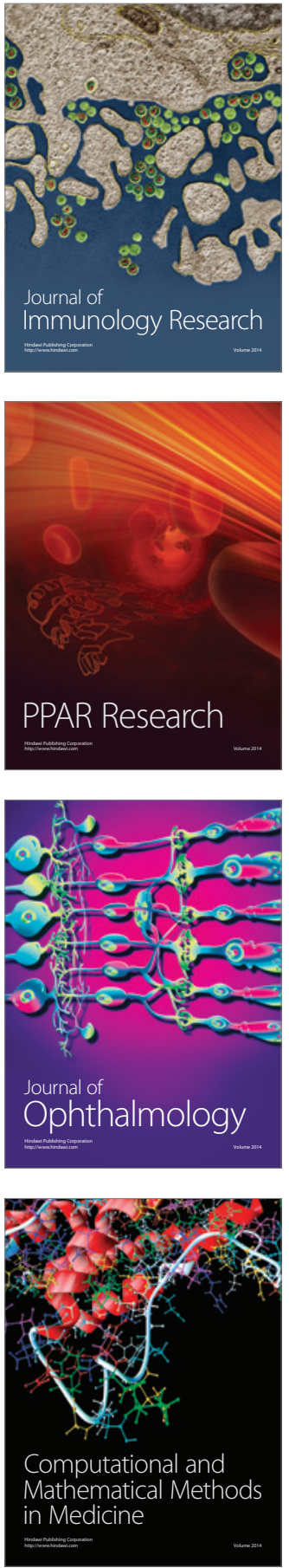

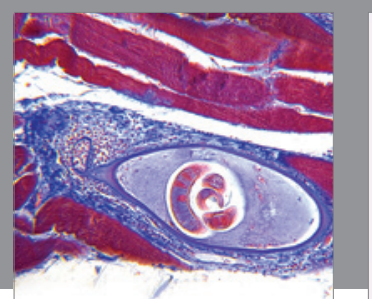

Gastroenterology Research and Practice

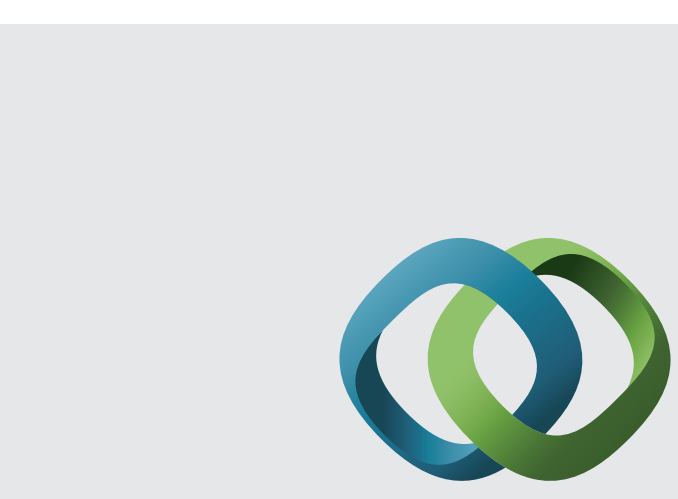

\section{Hindawi}

Submit your manuscripts at

http://www.hindawi.com
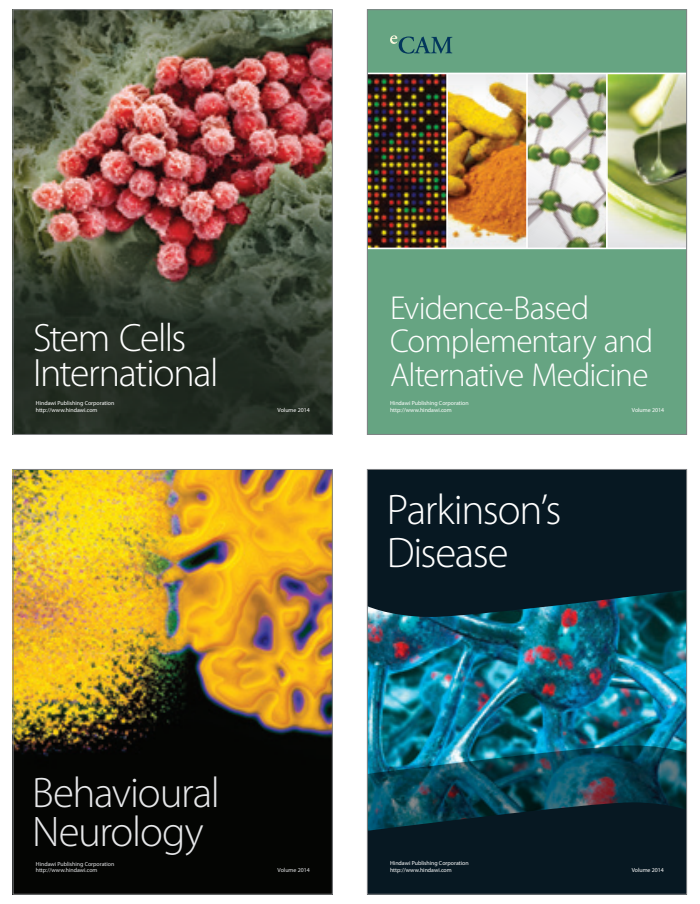
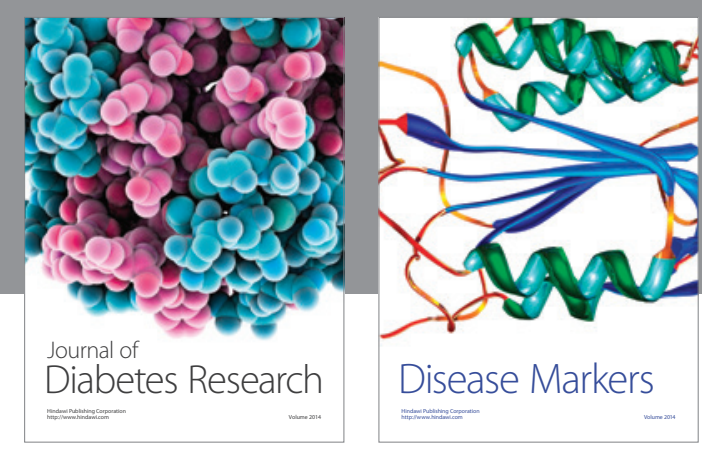

Disease Markers
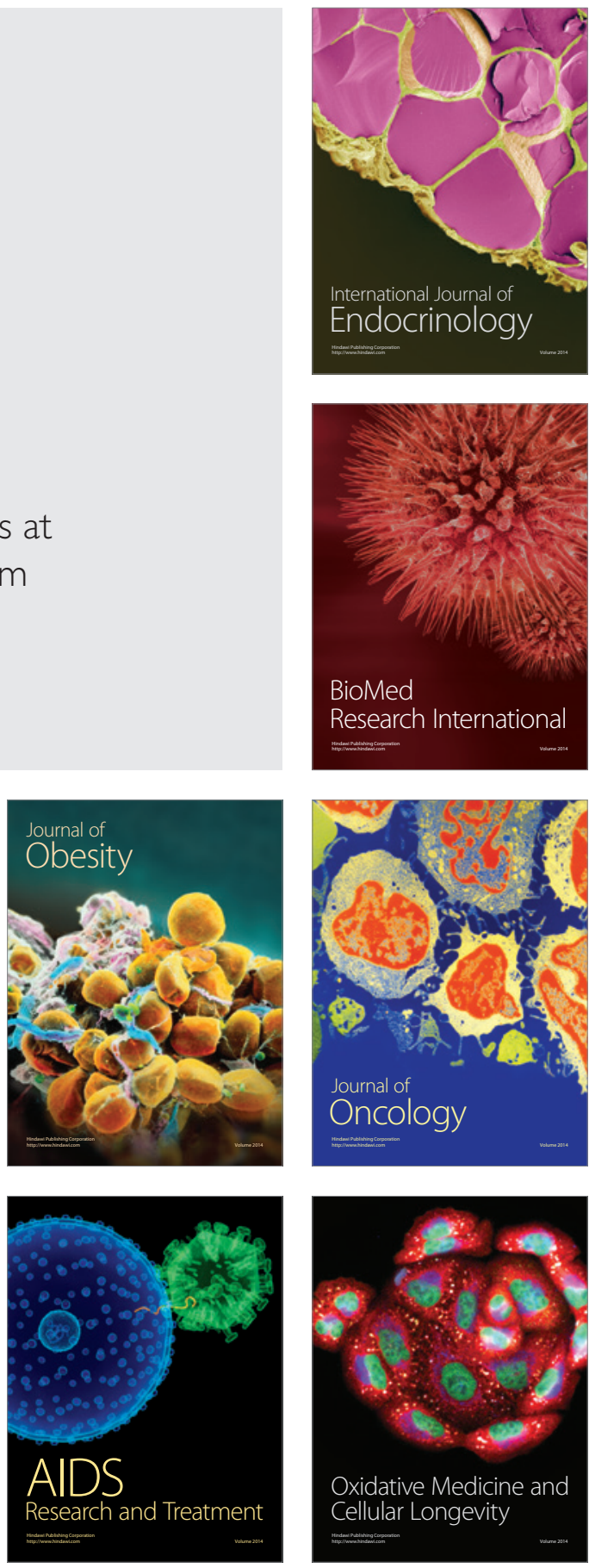